\title{
Proton-Controlled Reduction of ZnO Nanocrystals: Effects of Molecular Reductants, Cations, and Thermodynamic Limitations
}

Carolyn N. Valdez, ${ }^{\dagger \S}$ Alina M. Schimpf, ${ }^{\S}$ Daniel R. Gamelin, ${ }^{\S}$ and James M. Mayer*†

†Department of Chemistry, Yale University, New Haven, CT 06520-8107, USA

${ }^{\S}$ Department of Chemistry, University of Washington, Box 351700, Seattle, Washington 98195-1700, USA

\section{Table of Contents.}

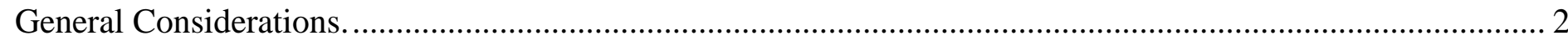

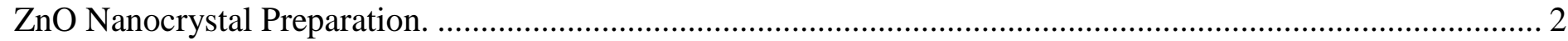

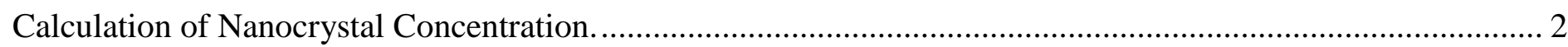

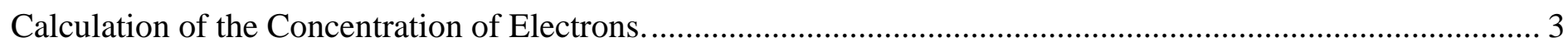

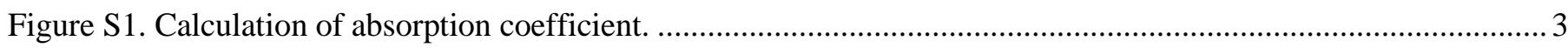

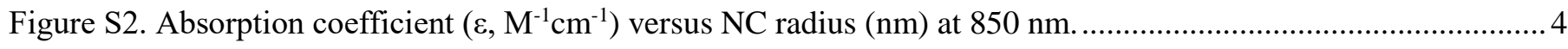

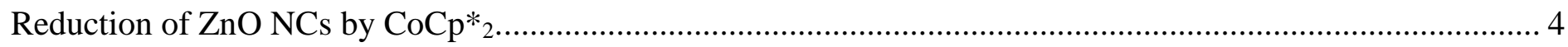

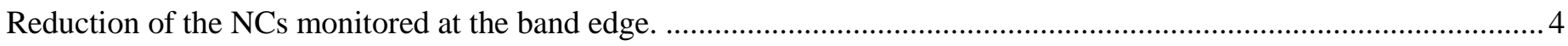

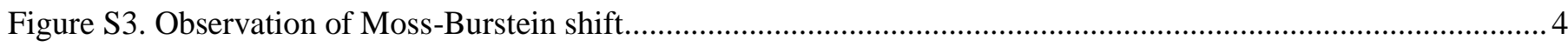

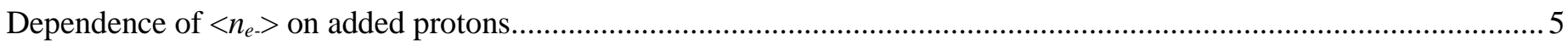

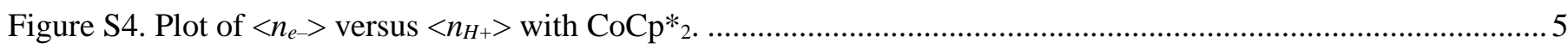

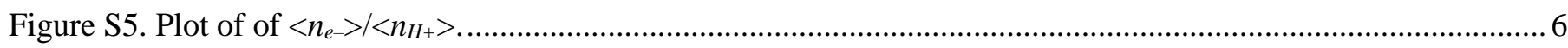

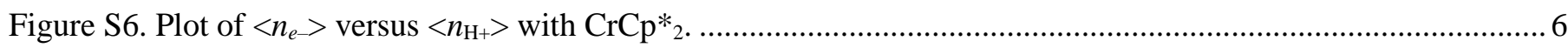

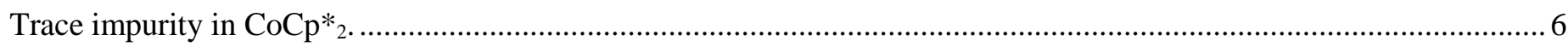

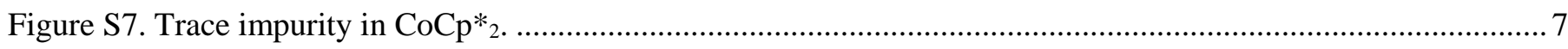

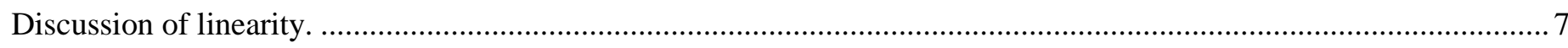

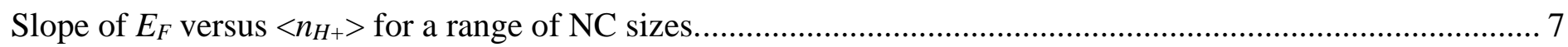

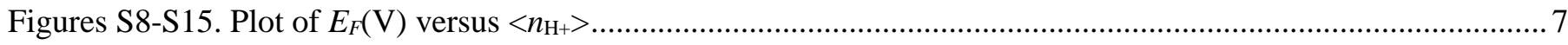

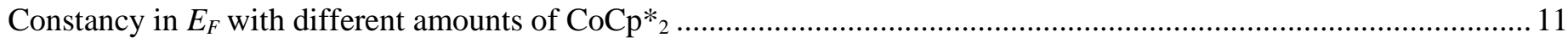

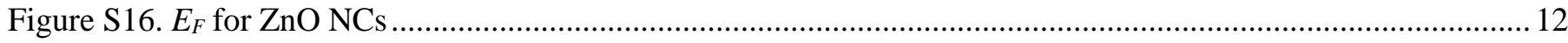

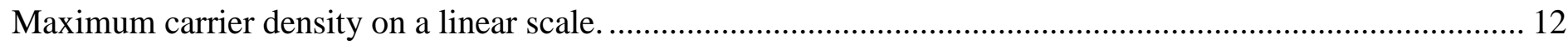

Figure S17. NC Size-Independent Carrier Density of ZnO NCs Reduced with CoCp* ${ }_{2}$ and Protons........................ 12

Figure S18. NC Size-Independent Carrier Density of ZnO NCs Reduced with $\mathrm{CrCp}_{2}{ }_{2}$ and Protons. ....................... 13

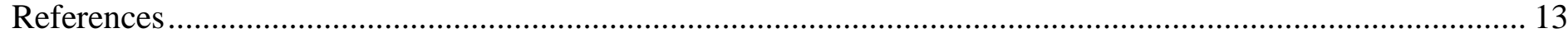


General Considerations. Zinc acetate dihydrate, tetramethylammonium hydroxide, dodecylamine (DDA), trioctylphosphine oxide (technical grade, 90\%), isopropylmagnesium chloride, and 1,3-bis(trifluoromethyl)-5bromobenzene were purchased from Aldrich and used as received. The base 1-tert-butyl-4,4,4tris(dimethylamino)-2,2-bis[tris(dimethylamino)-phos-phoranylidenamino]- $2 \lambda^{5}, 4 \lambda^{5}$-catenadi(phosphazene) (P4 phosphazene base, 1.0 $\mathrm{M}$ in hexanes) was purchased from Aldrich, dried down to a solid, and recrystallized from pentane before use. Sodium tetrafluoroborate, bis(pentamethylcyclopentadienyl) cobalt (decamethylcobaltocene, CoCp*2), bis(pentamethylcyclopentadienyl)chromium (CrCp*2) and 2,4,6-tri-tertbutylphenol $\left({ }^{t} \mathrm{Bu}_{3} \mathrm{ArOH}\right)$ were obtained from Aldrich and were dried in a vacuum oven, recrystallized from pentane $\left(\mathrm{MCp}^{*}{ }_{2}\right)$ or ethanol, respectively, before use. The corresponding phenoxyl radical ${ }^{t} \mathrm{Bu}_{3} \mathrm{ArO}^{\bullet}{ }^{\mathrm{was}}$ prepared according to the literature procedure. ${ }^{1}$ The oxidation purity of $\mathrm{CoCp}^{*}{ }_{2}$ was confirmed using ${ }^{1} \mathrm{H}$ NMR. $\left[\mathrm{H}\left(\mathrm{Et}_{2} \mathrm{O}\right)_{2}\right]\left[\mathrm{BAr}_{4}{ }_{4}\right]$ was synthesized using reported literature procedures ${ }^{2}$ from $[\mathrm{Na}]\left[\mathrm{BAr}_{4}\right]^{3}$ (dried in a vacuum oven for at least 24 hours) and $\mathrm{HCl}$. Bis(pentamethylcyclopentadienyl)iron ( $\mathrm{FeCp}_{2}$ ) was purchased from Strem and used as received. The oxidized product $\left[\mathrm{FeCp}^{*}{ }_{2}\right]\left[\mathrm{BAr} \mathrm{F}_{4}\right]\left(\mathrm{BAr}_{4}^{-}=\left[\mathrm{B}\left(\mathrm{C}_{6} \mathrm{H}_{3}\left(\mathrm{CF}_{3}\right)_{4}\right)\right]^{-}\right)$was prepared via adapted literature procedures. ${ }^{4,5}$ All solvents were purchased from Fischer Scientific and were dried using a Seca Solvent System installed by Glass Contour. Fluka TraceCERT ${ }^{\circledR}$ High Purity brand Zn standard (1000 $\mu \mathrm{g} / \mathrm{L}$ in $2 \% \mathrm{HCl}$ ) was used as the standard for ICP-OES (inductively coupled plasma-optical emission spectrometry).

All samples were prepared under $\mathrm{N}_{2}$. UV-vis spectra were recorded in an $\mathrm{N}_{2}$-filled glovebox using an Agilent Cary 5000 spectrometer. The data were processed using Igor Pro Version 6.22A. Other UV-vis spectra were obtained on a Hewlett Packard 8453 diode array spectrophotometer. Inductively-coupled plasma opticalemission spectroscopy (ICP-OES) was carried out using a Perkin Elmer Optima 8300.

ZnO Nanocrystal Preparation. Nanocrystals (NCs) were prepared following reported procedures with minor modifications. ${ }^{6,7}$ For small NCs, at $0{ }^{\circ} \mathrm{C}$ under air, a solution of $\mathrm{Me}_{4} \mathrm{~N}(\mathrm{OH}) \cdot 5 \mathrm{H}_{2} \mathrm{O}$ (tetramethylammonium hydroxide, $13.3 \mathrm{~g}, 7.3 \mathrm{mmol}$ ) in $140 \mathrm{~mL}$ of ethanol was added to a stirring solution of zinc acetate $\left(\mathrm{Zn}(\mathrm{OAc})_{2} \cdot 2 \mathrm{H}_{2} \mathrm{O}, 10.0 \mathrm{~g}, 4.6 \mathrm{mmol}\right)$ in $300 \mathrm{~mL}$ DMSO and $150 \mathrm{~mL}$ ethanol, at a rate of $\sim 5 \mathrm{~mL} / \mathrm{minute}$. After 60 minutes of stirring, NCs were precipitated from the clear solution with the addition of $\sim 800$ mL ethyl acetate until the solution was cloudy and white. The NCs were isolated from the solution by centrifugation in six separate tubes followed by decantation. The resulting white pellets were washed twice to remove excess starting material by iterative dissolution of each pellet in $2 \mathrm{~mL}$ of ethanol and precipitation with $10 \mathrm{~mL} n$-heptane. The NCs were then capped by dissolving each pellet in $1 \mathrm{~mL}$ molten DDA $\left(120-160{ }^{\circ} \mathrm{C}\right)$, consolidated in one test tube, and allowed to rest for $5-10$ minutes. For larger NCs, the DDA solution was heated for a longer period of time (10 minutes -1 hour) at $170{ }^{\circ} \mathrm{C}$. After cooling, NCs were precipitated from solution with the addition of $\sim 5 \mathrm{~mL}$ ethanol. The white solid was collected by centrifugation and decantation and dried under vacuum for five minutes. The white solid was brought into an $\mathrm{N}_{2}$ glovebox, dissolved in $\sim 20 \mathrm{~mL}$ of toluene to give a colorless solution and stored in the freezer $\left(-35^{\circ} \mathrm{C}\right)$. The average NC diameter was calculated from the UVvisible absorption spectrum using the experimentally derived relationship between diameter and the energy of the band gap absorbance ${ }^{8}(r<3.5 \mathrm{~nm})$ or from TEM $(r>3.5 \mathrm{~nm})$.

Calculation of Nanocrystal Concentration. An aliquot $(0.1 \mathrm{~mL})$ of room temperature $\mathrm{ZnO} \mathrm{NCs}$ in toluene was dried under vacuum, and the sample was calcined at $500{ }^{\circ} \mathrm{C}$ for at least 2 hours to remove residual organic matter. After calcination, samples were digested in EMD OmniTrace ${ }^{\circledR} \mathrm{HNO}_{3}$ and diluted to a volume of $5 \mathrm{~mL}$ with deionized water in a volumetric flask. Five samples were then prepared for ICP analysis and the concentration determined by the method of standard additions. Each of the five samples contained a $100 \mu \mathrm{L}$ aliquot of the $5 \mathrm{~mL}$ calcined $\mathrm{ZnO}$ sample and $0,50,150,300$, and $500 \mu \mathrm{L}$ of $\mathrm{Zn}$ standard $(1000 \mu \mathrm{g} / \mathrm{mL}$ in $2 \%$ $\mathrm{HCl}$ ), and were diluted with deionized water in $10 \mathrm{~mL}$ volumetric flasks. The intensity of the atomic emission spectrum for $\mathrm{Zn}$ was recorded by ICP for each sample and used to extrapolate the concentration of $\mathrm{Zn}$ in the original sample, using the $\mathrm{x}$-intercept for the linear fit of a plot of $\mathrm{Zn}$ intensity vs. [Zn added]. The average volume of each $\mathrm{ZnO} \mathrm{NC}$ was calculated assuming a spherical $\mathrm{NC}$ with ${ }^{4} / 3 \pi \mathrm{r}^{3}$, where $\mathrm{r}$ is the radius determined 
from the optical spectra (see above). Crystalline wurtzite $\mathrm{ZnO}$ has a unit cell volume of $47.66 \AA^{3}$ with two formula units per unit cell. Thus the average number of $\mathrm{Zn}$ atoms per $\mathrm{NC}$ is $\left(2 \times{ }^{4} / 3 \pi \mathrm{r}^{3}\right) \div 47.66 \AA^{3}$. The concentration of NCs is given by dividing the total $\mathrm{Zn}$ concentration (determined by ICP) by the number of $\mathrm{Zn}$ atoms per NC.

Calculation of the Concentration of Electrons. In a typical experiment, an anaerobic solution of ZnO NCs in toluene or 50/50 v/v toluene/THF $\left(10^{-3}-10^{-5} \mathrm{M}\right)$ was placed in a quartz Kontes cuvette equipped with a stir bar, and irradiated while stirring for 1-60 minutes approximately $10 \mathrm{~cm}$ from the lamp aperture with a Newport 100 W Hg lamp. The reduced solutions were taken into a $\mathrm{N}_{2}$ glovebox where titrations were carried out using the Cary 5000 spectrometer described above. In a typical titration, twenty $10 \mu \mathrm{L}$ aliquots of reagent (e.g. $\sim 0.1 \mathrm{M}$ solution of ${ }^{t} \mathrm{Bu}_{3} \mathrm{ArO} \bullet$ in toluene) were added to $2 \mathrm{~mL}$ of a $5 \times 10^{-4} \mathrm{M}$ solution of reduced $\mathrm{ZnO} \mathrm{NCs}$ in a cuvette, while stirring. The optical spectra were recorded 30 seconds after each addition.

The concentration of electrons in solution was calculated using the amount of ${ }^{t} \mathrm{Bu}_{3} \mathrm{ArO}{ }^{\bullet}$ added (Figure $\mathrm{S} 1$ ), to give an extinction coefficient per electron at $850 \mathrm{~nm}\left(\varepsilon=1000 \pm 200 \mathrm{M}^{-1} \mathrm{~cm}^{-1}\right.$ for small NCs $) .{ }^{9}$ For larger NCs, the extinction coefficient was not $1000 \mathrm{M}^{-1} \mathrm{~cm}^{-1}$ at $850 \mathrm{~nm}$, as shown in Figure S2. All wavelengths between 400 and $2100 \mathrm{~nm}$ could be monitored, but the absorption coefficient does not follow Beer's law closer to the peak maximum (longer wavelengths). Due to spectrometer limits and variation from Beer's law at longer wavelengths, the absorbance at $850 \mathrm{~nm}$ is used to determine the concentration of electrons (Figure S1).
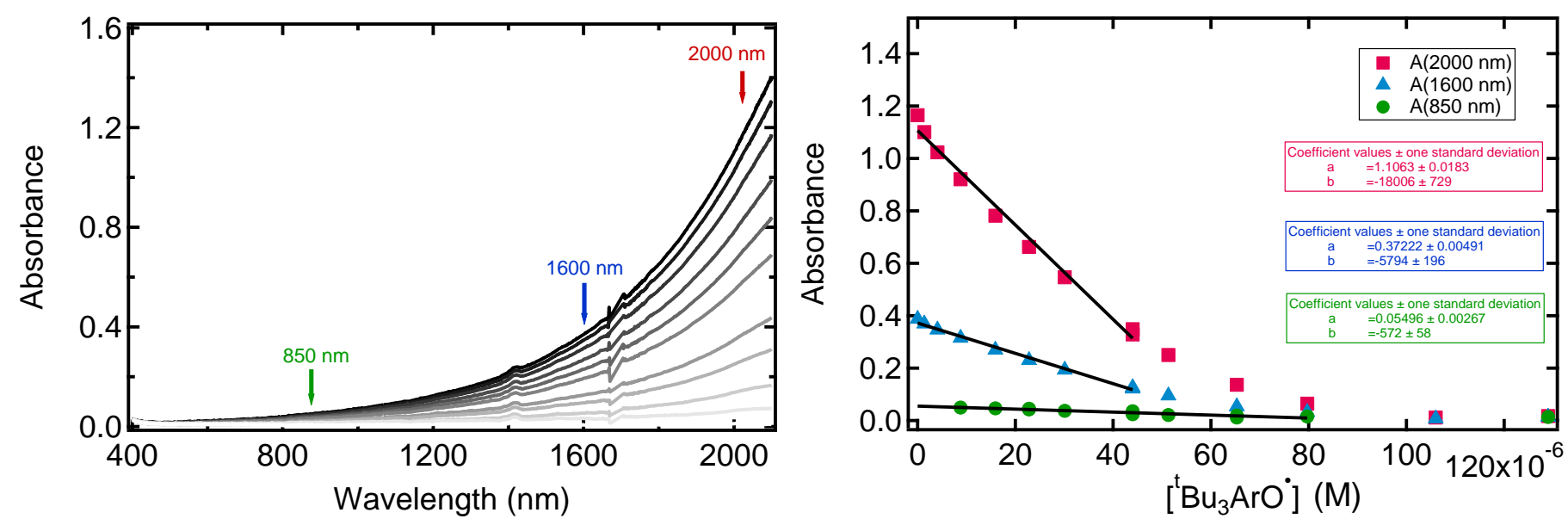

Figure S1. Calculation of absorption coefficient. An example experiment for the oxidation of photoreduced $\mathrm{ZnO}$ NCs $\left(r=3.0 \mathrm{~nm}, 5.2 \times 10^{-6} \mathrm{M}\right.$, TOPO ${ }^{*}$-capped) with ${ }^{t} \mathrm{Bu}_{3} \mathrm{ArO}{ }^{\bullet}$. Left: Absorption spectrum as a solution of ${ }^{t} \mathrm{Bu}_{3} \mathrm{ArO}^{\bullet}$ in toluene is added (not linear, as aliquots were taken out for IR analysis). Right: The absorbance is plotted as a function of [ $\left.{ }^{t} \mathrm{Bu}_{3} \mathrm{ArO}{ }^{\bullet}\right]$, monitored at $850 \mathrm{~nm}$ (green circles), $1600 \mathrm{~nm}$ (blue triangles), and $2000 \mathrm{~nm}$ (red squares). Closer to the peak maximum at long wavelengths, the absorbance as phenoxyl is added is nonlinear, indicating that a linear absorption coefficient does not hold at $2000 \mathrm{~nm}$. At $850 \mathrm{~nm}$ the absorbance changes are linear with respect to $\left[{ }^{t} \mathrm{Bu}_{3} \mathrm{ArO}{ }^{\bullet}\right]$, indicating that using a molar absorption coefficient is appropriate. 


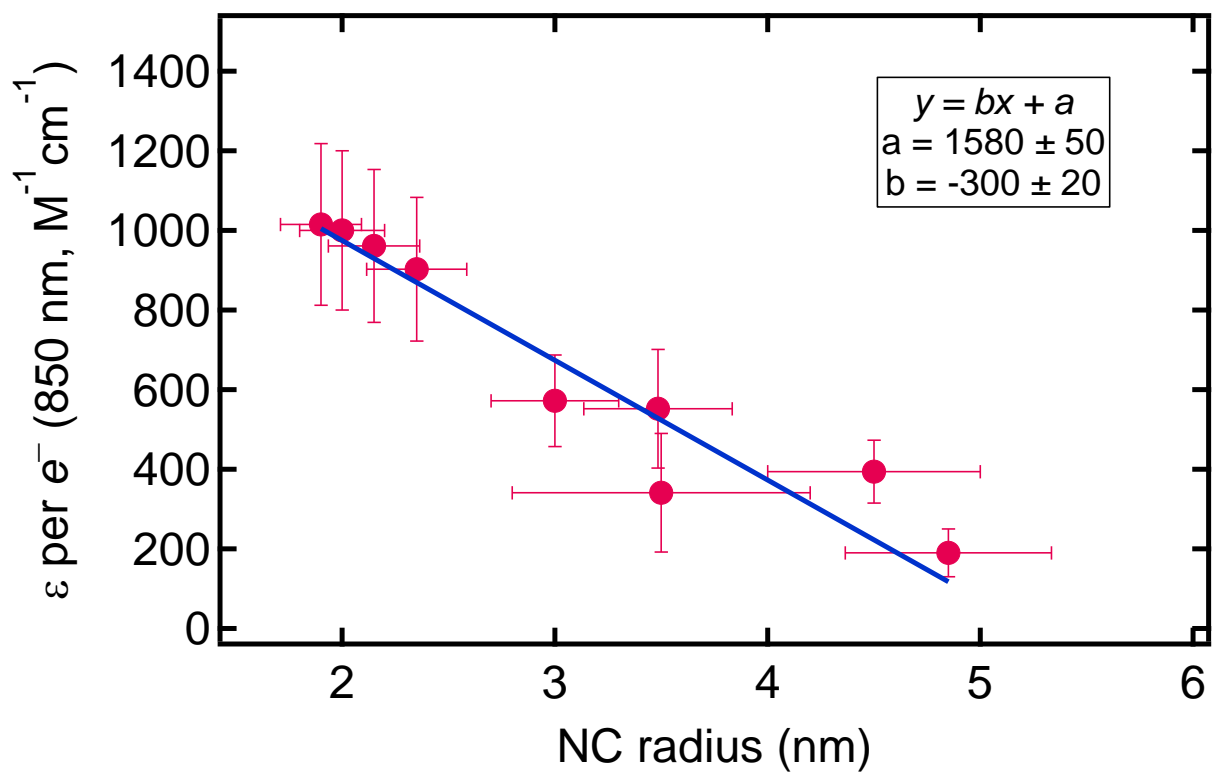

Figure S2. Absorption coefficient $\left(\varepsilon, \mathbf{M}^{-1} \mathbf{c m}^{-1}\right)$ versus $\mathrm{NC}$ radius $(\mathbf{n m})$ at $850 \mathbf{~ n m}$. NC sizes are calculated using the optical absorbance ${ }^{8}(r<3.5 \mathrm{~nm})$ or from TEM $(r>3.5 \mathrm{~nm})$. Uncertainties on the NC size are from the standard deviation from TEM or $10 \%$, whichever was greater. Uncertainties on the epsilon were calculated at $20 \%$, following our previous report. Although the data do not necessarily need to follow a trend, they fit well to $y=b x+a$ with a slope of $300 \mathrm{M}^{-1} \mathrm{~cm}^{-1}$ per $\mathrm{nm}$ in radius.

\section{Reduction of ZnO NCs by CoCp*2.}

Reduction of the NCs monitored at the band edge. The reduction of the NCs can also be observed at very low concentrations at the band edge $(\sim 350 \mathrm{~nm})$. As reductant and acid are added, the first excitonic absorption is bleached, consistent with the Moss-Burstein effect (Figure S3).

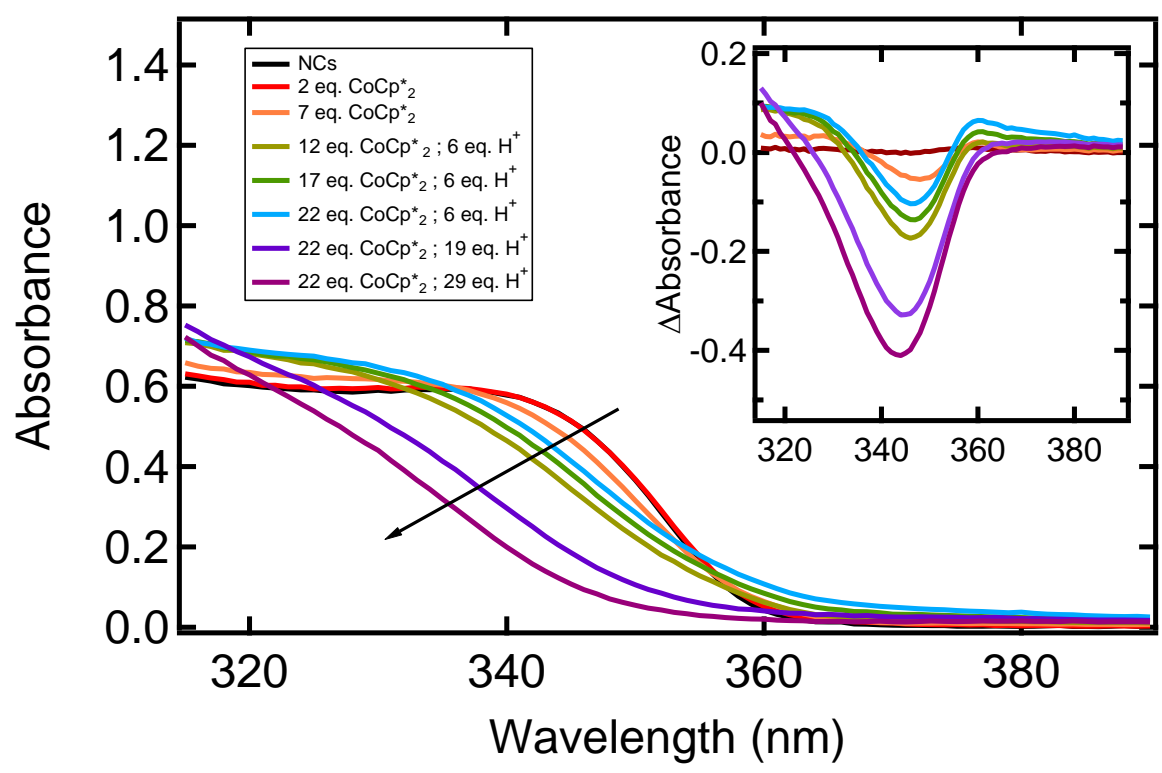

Figure S3. Observation of Moss-Burstein shift. Absorption spectrum of $\mathrm{ZnO}$ NCs $\left(r=1.9 \mathrm{~nm}, 6.5 \times 10^{-7} \mathrm{M}\right)$ in 50/50 toluene/THF, as $\mathrm{CoCp}_{2}{ }_{2}$ and DDA- $\mathrm{H}^{+}$is added. The inset shows the change in absorbance relative to the initial spectrum (no acid or reductant added). All are volume-corrected. 
Dependence of $\left\langle\boldsymbol{n}_{e_{-}}\right\rangle$on added protons. The average number of carriers per NC $\left(\left\langle n_{e_{-}}\right\rangle\right)$is plotted as a function of $\mathrm{H}^{+}$per $\mathrm{NC}\left(\left\langle n_{\mathrm{H}_{+}}\right\rangle\right)$) added in Figure $\mathrm{S} 4$. Almost all of the traces show linearity from the initial point of added acid until saturation at $\left\langle n_{e_{-}}\right\rangle_{\max }$. The slope of this line before saturation $\left(\left\langle n_{e_{-}}\right\rangle \mid\left\langle n_{\mathrm{H}_{+}}\right\rangle\right)$is near one for all samples $(0.9 \pm 0.3)$ (Figure S5). In some of the traces there is a small deviation from linearity at very low amounts of acid. The small variation in slopes and occasional low-acid deviations likely result in part from the difficulty of precise measurements of small amounts of strong acid in the glove box. There are also likely small variations in the NC suspensions from sample to sample, as some may have trace acid or base (perhaps surface hydroxide) and it is difficult to avoid trace impurities in solvents at the sub- $10^{-5} \mathrm{M}$ level. Consistent with this concern, the $\left\langle n_{e_{-}}\right\rangle \mid\left\langle n_{\mathrm{H}_{+}}\right\rangle$slopes are more likely to be $\langle 1$ for the smaller particles, where the amounts of added materials are less (Figure S4). We also notice that larger NCs typically deviate on the end of $\rangle 1\left\langle n_{e_{-}}\right\rangle \mid\left\langle n_{\mathrm{H}_{+}}\right\rangle$, which might arise from differences in the NC synthesis. Larger NCs are heated (see Methods section) which may remove trace acid. In addition, at larger amounts of $\mathrm{CoCp}_{2}^{*}$, a trace impurity consumes the first additions of acid (vide infra), which is only relevant for the larger NCs because the CoCp*2 must be at a much higher concentration. Although there are many experimental reasons to explain individual deviations from 1.0, the average $\left\langle n_{e_{-}}\right\rangle \mid\left\langle n_{\mathrm{H}_{+}}\right\rangle$of $0.9 \pm 0.3$ is statistically indistinguishable from 1 (Figure S5).

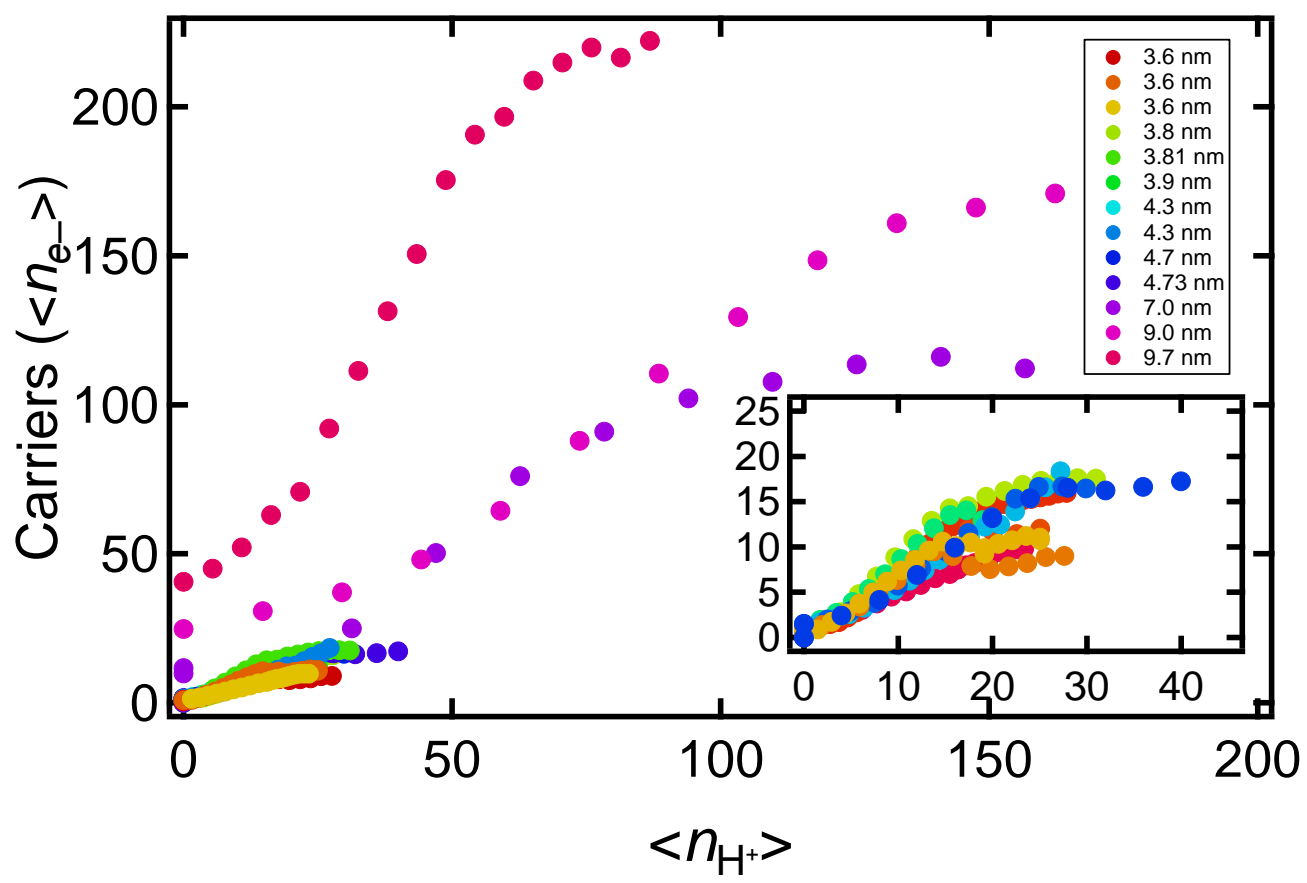

Figure S4. Plot of $\left\langle n_{e_{-}}\right\rangle$versus $\left\langle n_{H_{+}}\right\rangle$with $\mathbf{C o C p} *_{2}$. The average number of carriers per NC $\left(\left\langle n_{e_{-}}\right\rangle\right)$added with $\mathrm{CoCp}^{*}$, plotted as a function of $\left\langle n_{\mathrm{H}_{+}}\right\rangle$, for a variety of NC sizes. The legend gives the NC diameter, from $3.6 \mathrm{~nm}$ to $9.7 \mathrm{~nm}$. The inset shows the smaller NCs. 


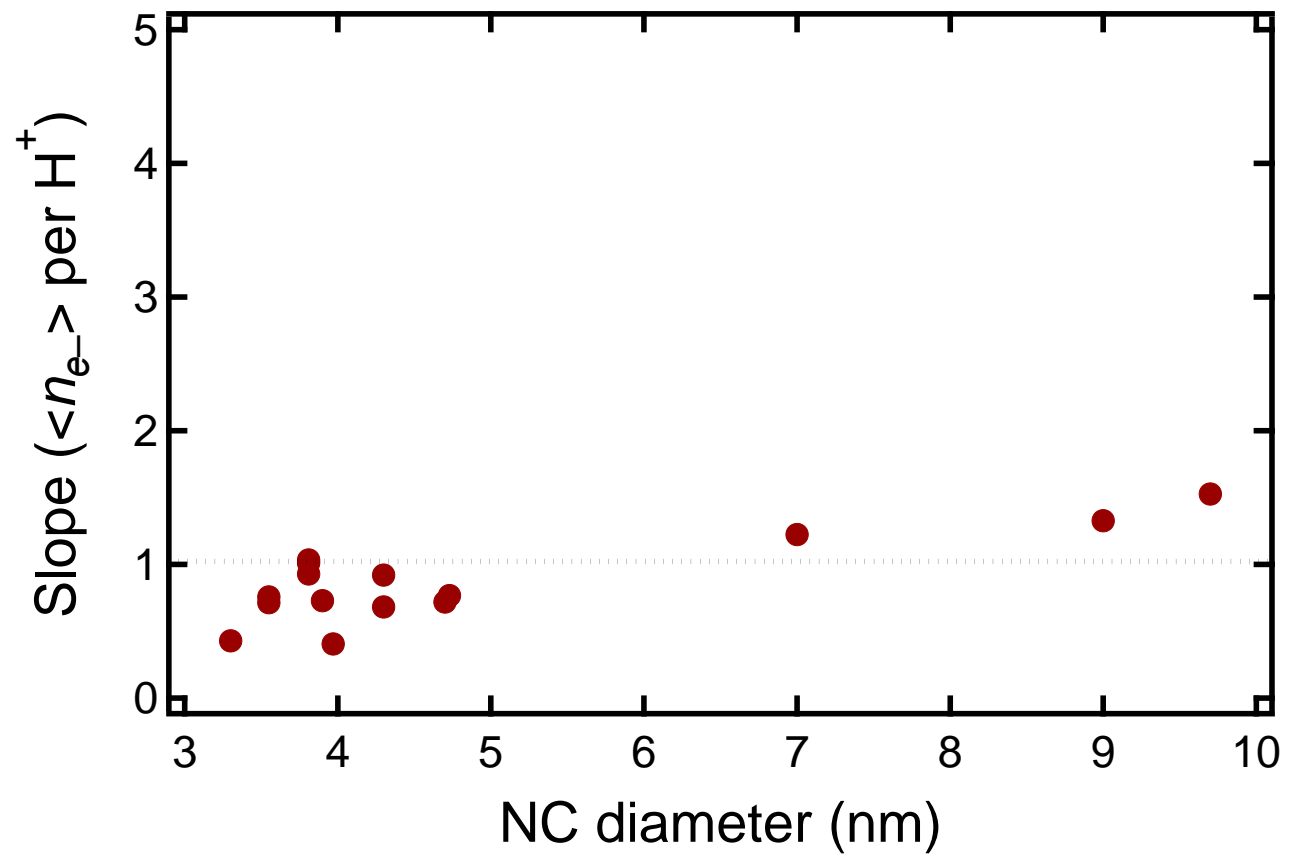

Figure S5. Plot of $\left\langle\boldsymbol{n}_{e_{-}}\right\rangle \mid\left\langle\boldsymbol{n}_{\boldsymbol{H}_{+}}\right\rangle$. The slope from Figure $\mathrm{S} 4$ is plotted as a function of NC diameter. The dotted line represents $\left\langle n_{e^{-}}\right\rangle /\left\langle n_{H^{+}}\right\rangle=1$.

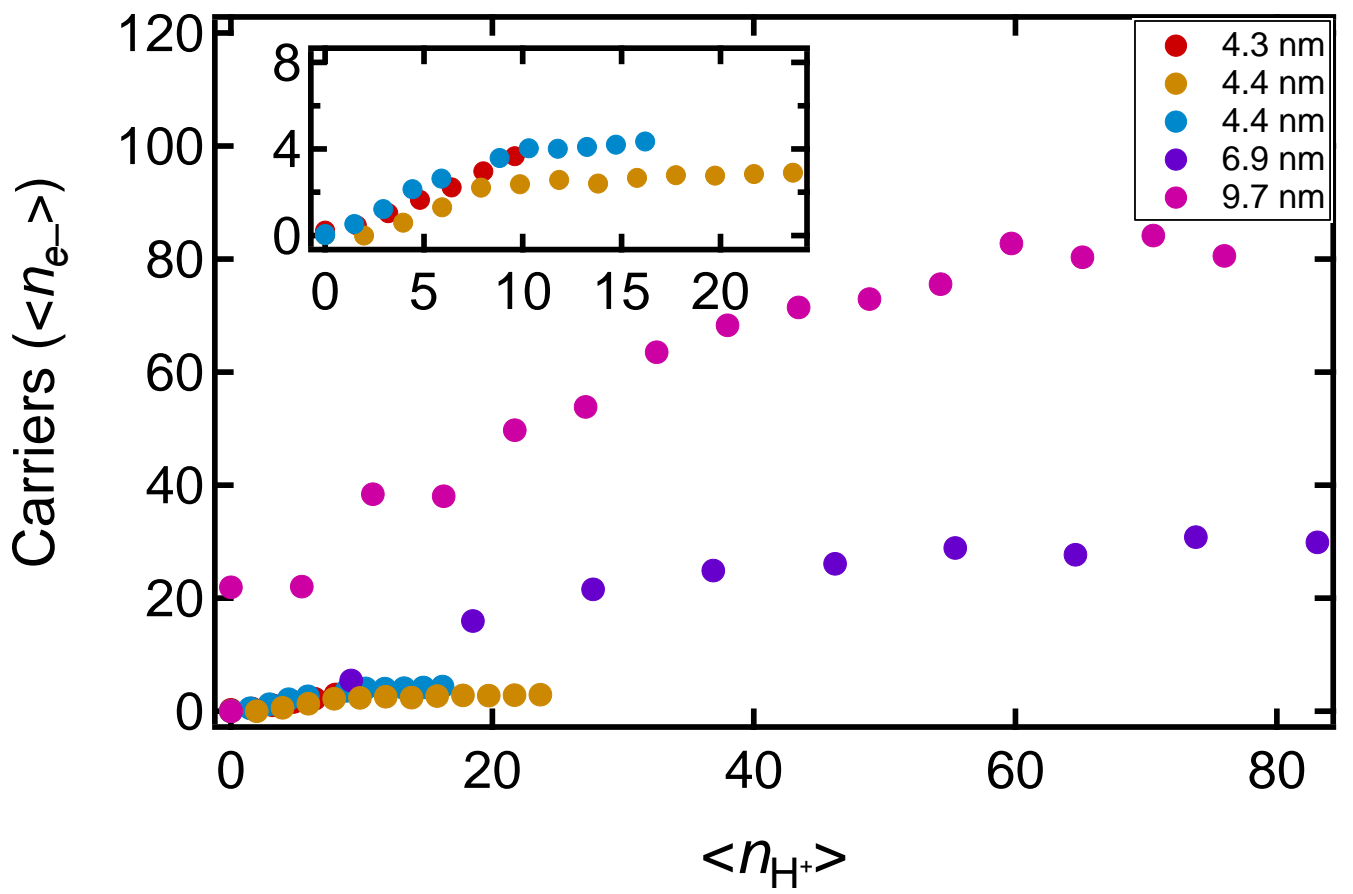

Figure S6. Plot of $\left\langle\boldsymbol{n}_{e_{-}}\right\rangle$versus $\left\langle\boldsymbol{n}_{\mathrm{H}_{+}}\right\rangle$with $\mathbf{C r C p} *_{2}$. The average number of carriers per NC $\left(\left\langle n_{e_{-}}\right\rangle\right)$added with $\mathrm{CrCp}_{2}{ }_{2}$, plotted as a function of $\left\langle n_{\mathrm{H}_{+}}\right\rangle$, for a variety of NC sizes. The legend gives the NC diameter, from $4.3 \mathrm{~nm}$ to $9.7 \mathrm{~nm}$. The inset shows the smaller NCs.

Trace impurity in $\boldsymbol{C o C p}_{2}{ }_{2}$. A trace impurity is occasionally present in $\mathrm{CoCp}_{2}{ }_{2}$ with a $\lambda_{\max }$ at $640 \mathrm{~nm}$. Repeated filtering or recrystallizations in pentane did not remove this impurity, and it was not present in all samples. The impurity is consumed by the first additions of acid (Figure S7), which explains the sigmoidal shape at very 
small amounts of acid. There is more impurity present in the case with $600 \mathrm{CoCp}_{2}{ }_{2}$ versus 60 equivalents per NC. It's consumed by the acid at 10 equivalents of $\mathrm{H}^{+}$per $\mathrm{NC}$, which suggests that the impurity is present in $<2 \%$, which explains why the curved shape is mainly observed with large NCs, where much high concentrations of $\mathrm{CoCp}_{2}{ }_{2}$ were necessary.
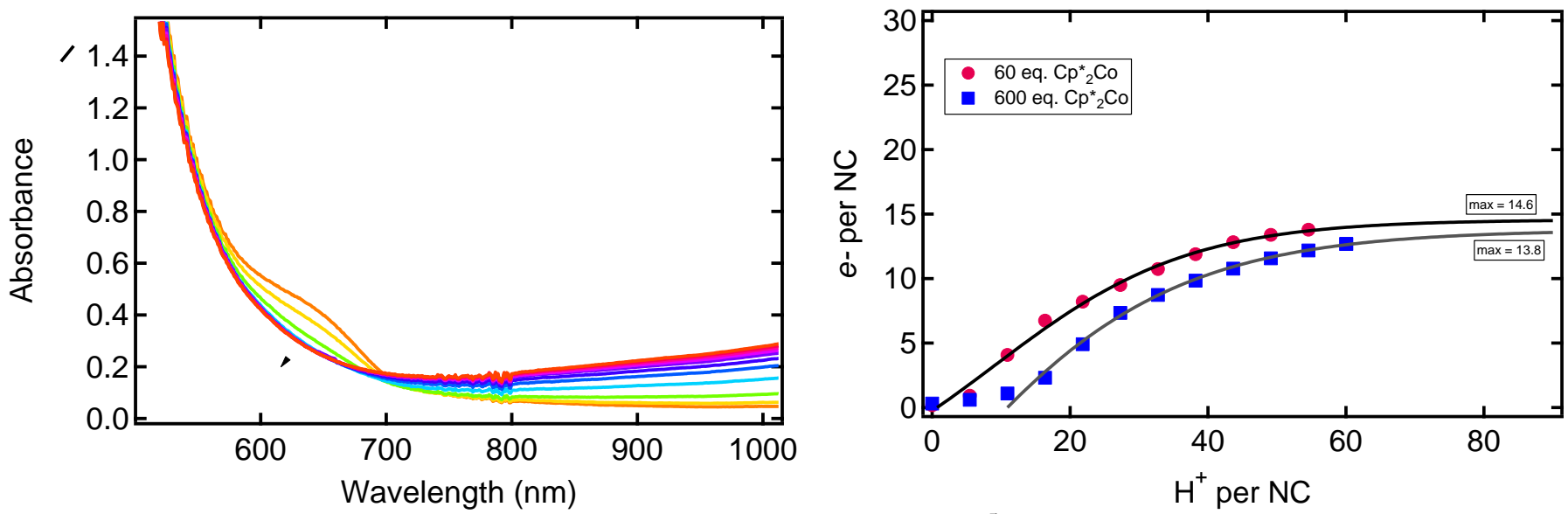

Figure S7. Trace impurity in CoCp ${ }^{2}$. NCs $\left(r=1.9 \mathrm{~nm}, 1.8 \times 10^{-5} \mathrm{M}\right.$, TOPO*-capped) reduced with CoCp* ${ }_{2}$, 60 equivalents (red circles) and 600 equivalents (blue squares). Electrons per NC monitored at $1600 \mathrm{~nm}$ as a function of acid added as a toluene/THF solution of [DDA-H] $\left[\mathrm{BAr}^{\mathrm{F}}\right.$ ] $\left(10 \mu \mathrm{L}, 1.8 \times 10^{-2} \mathrm{M}\right.$ stock). Data are fit to a sigmoid curve, and approximately the same $\left\langle n_{e_{-}}\right\rangle_{\max }$ is reached at 13.8 and 14.6 electrons per NC, respectively.

Discussion of linearity. As described in the main text, the linearity of $\left\langle n_{e_{-}}\right\rangle$with respect to added protons is surprising based on the hydrogenic atom-like orbitals predicted for delocalized electrons in nanomaterials. ${ }^{10}$ The linearity can be explained by a variety of reasons: surface states, heterogeneity based on NC size distribution, or surface dipole effects. The contribution of surface states to the linear behavior may be ruled out because of the lack of appreciable trap states on $\mathrm{ZnO}$, as evidenced by EPR for photochemically reduced $\mathrm{ZnO} \mathrm{NCs}^{11}$ and with reductants and acid. ${ }^{4}$ TEM images show typical standard deviations of NC diameter of $\sim 1 \mathrm{~nm}$, which corresponds to approximately $100 \mathrm{meV}$ in conduction band shift. ${ }^{7}$ However, the uncertainties in these estimates mean that this explanation for the linearity cannot be ruled out. Inhomogeneous broadening due to surface dipole effects is difficult to quantify, and cannot be ruled out a priori. Another explanation for the linearity is that the cations significantly change the electronic structure, either splitting the degeneracy of the orbitals leading to an electronic structure more like a continuous degenerate band than discrete orbitals. Recently, we showed computationally that a single $\mathrm{Al}^{3+}$ dopant in a small $\mathrm{ZnO} \mathrm{NC}$ does split the degeneracy of, for instance, the $p$-like orbitals. ${ }^{12}$ However, the splittings were still small relative to the $s-p$ and $p$ - $d$ energy gaps. In addition, the calculations included one dopant atom, and the system described here likely has $>100$ protons per NC so the asymmetry is likely to be small. Thus a break in degeneracy due to cation binding is not sufficient to describe the observed linearity. A dramatic change in the electronic structure of the NCs by the presence of the cation is also unlikely because the EPR spectra are almost invariant to the nature of the cation. ${ }^{4}$

\section{Slope of $E_{F}$ versus $<n_{\mathrm{H}+}>$ for a range of $\mathrm{NC}$ sizes.}

Figures S8-S15. Plot of $\boldsymbol{E}_{\boldsymbol{F}}(\mathrm{V})$ versus $\left\langle n_{\mathrm{H}+}\right\rangle$, similar to Figure 5B in the main text. $E_{F}$ is calculated using equation 1 and $\left\langle n_{\mathrm{H}+}\right\rangle$ is known from the amount of acid added. The line of best fit and NC radius is given in the upper right corner. 

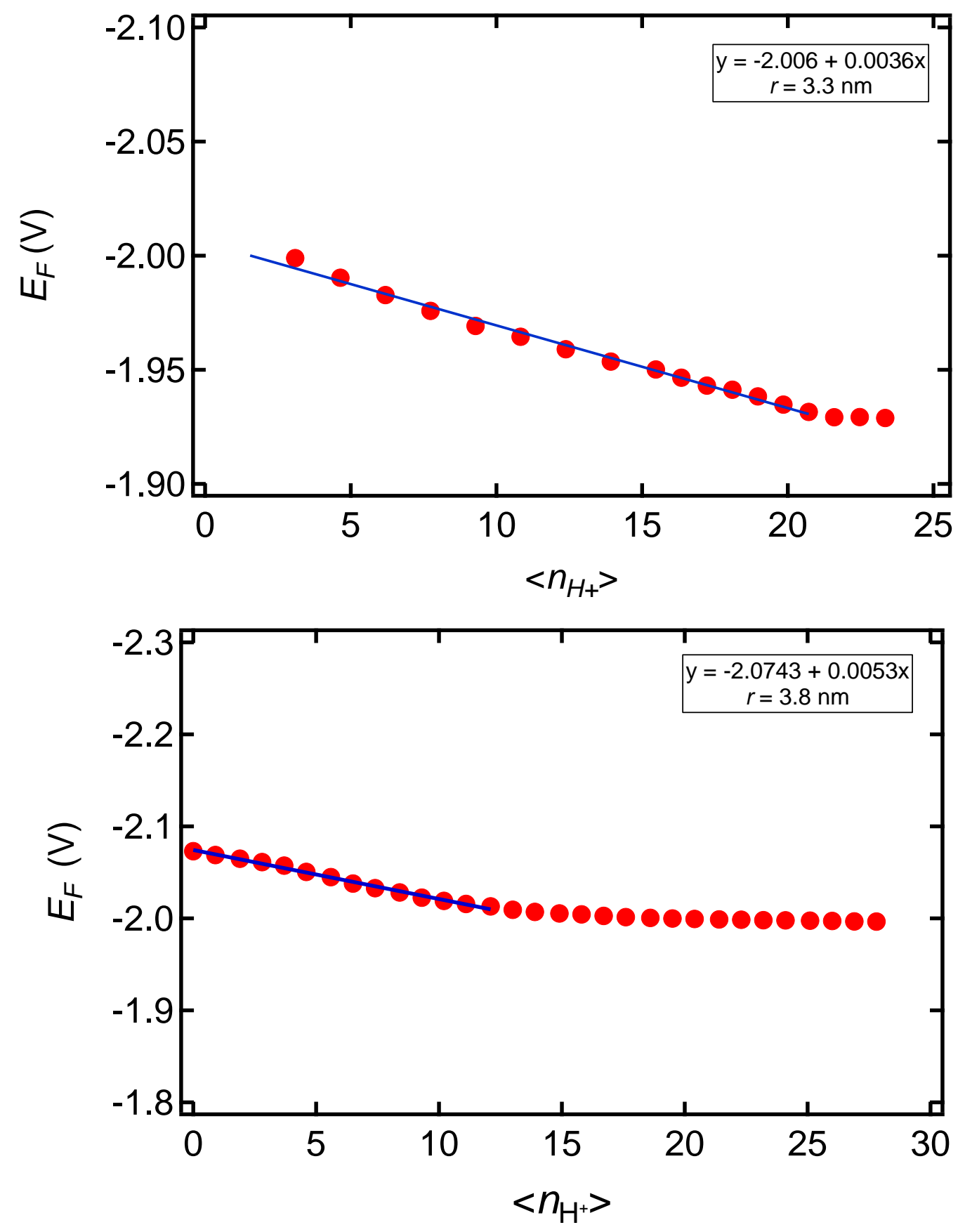

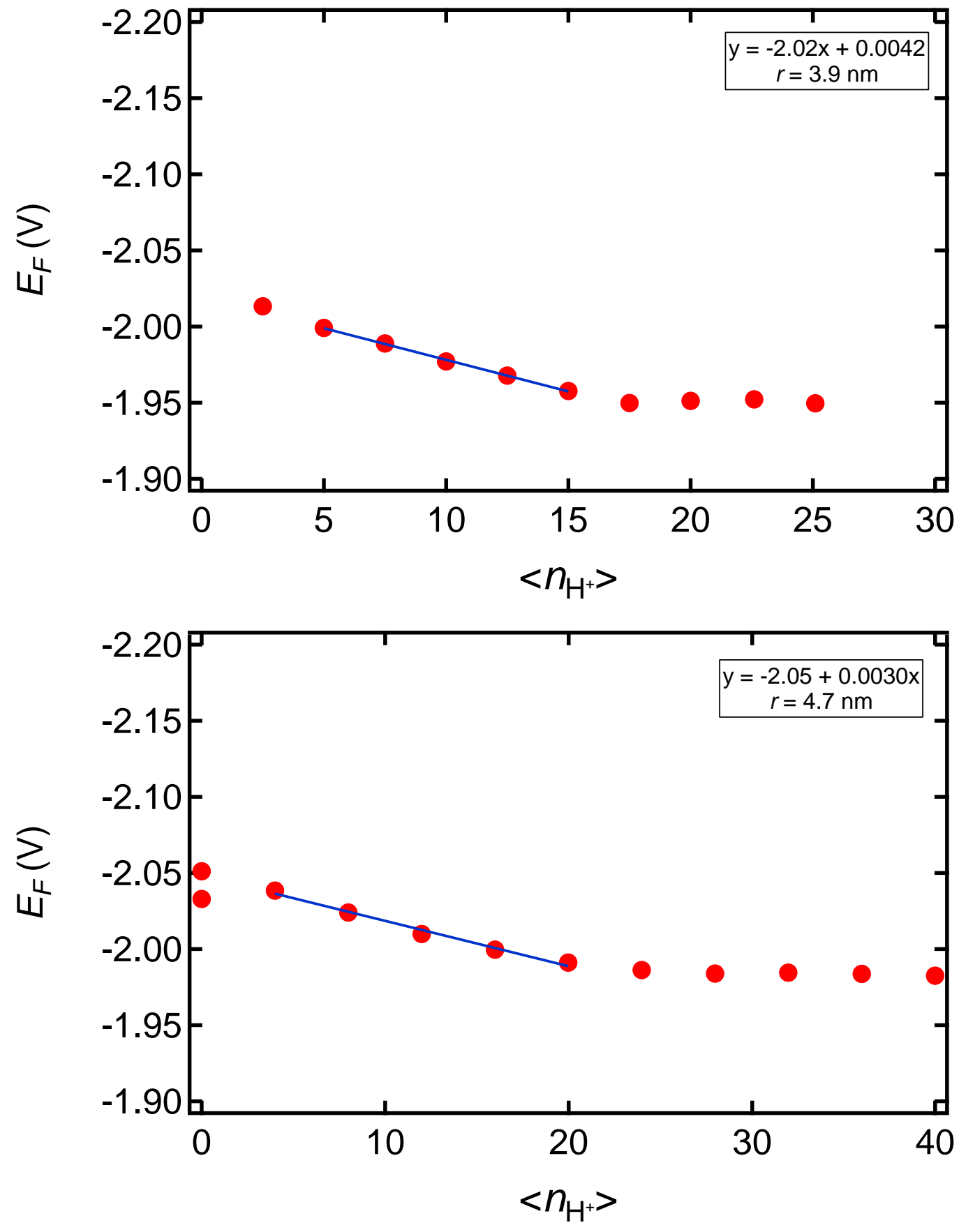

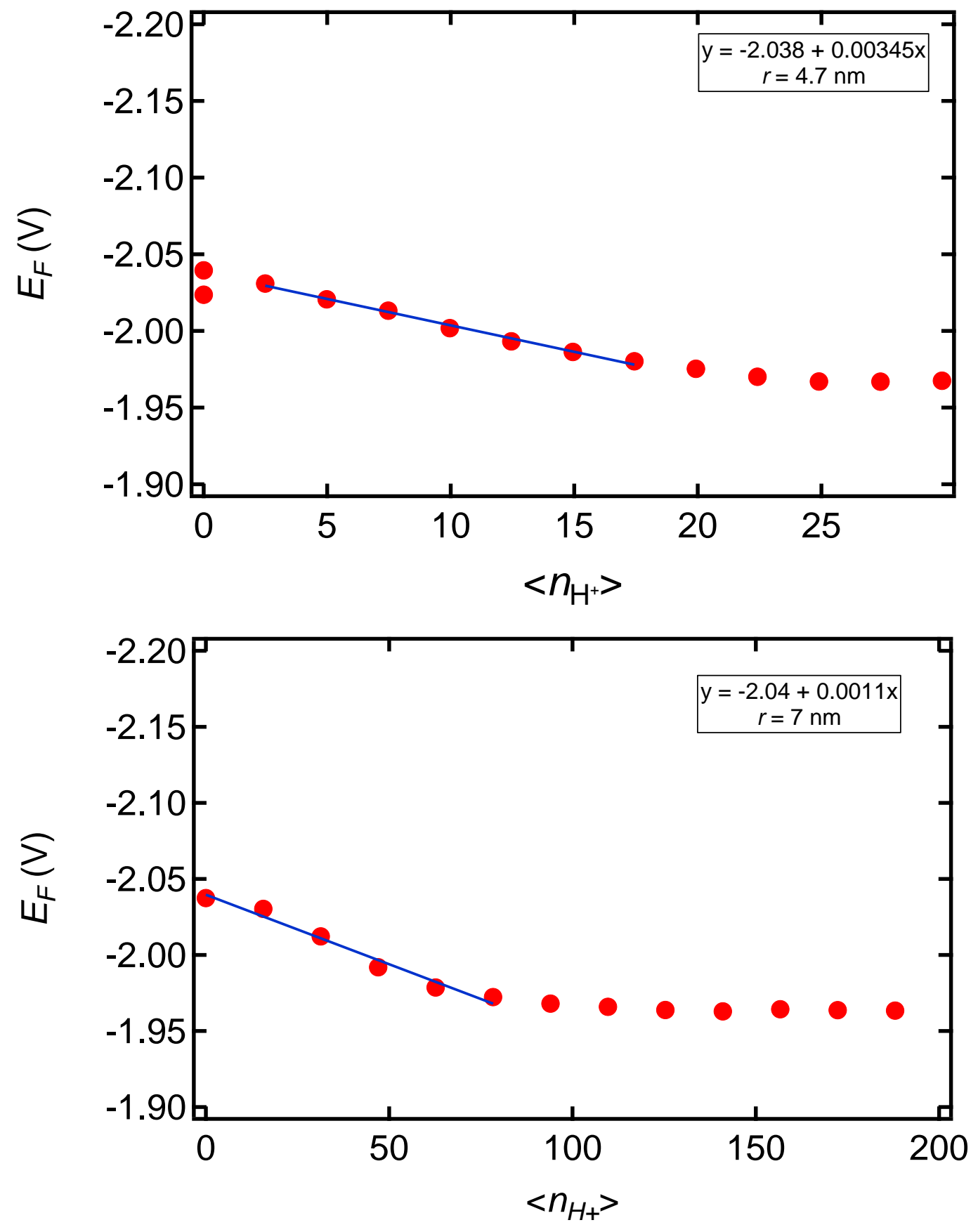

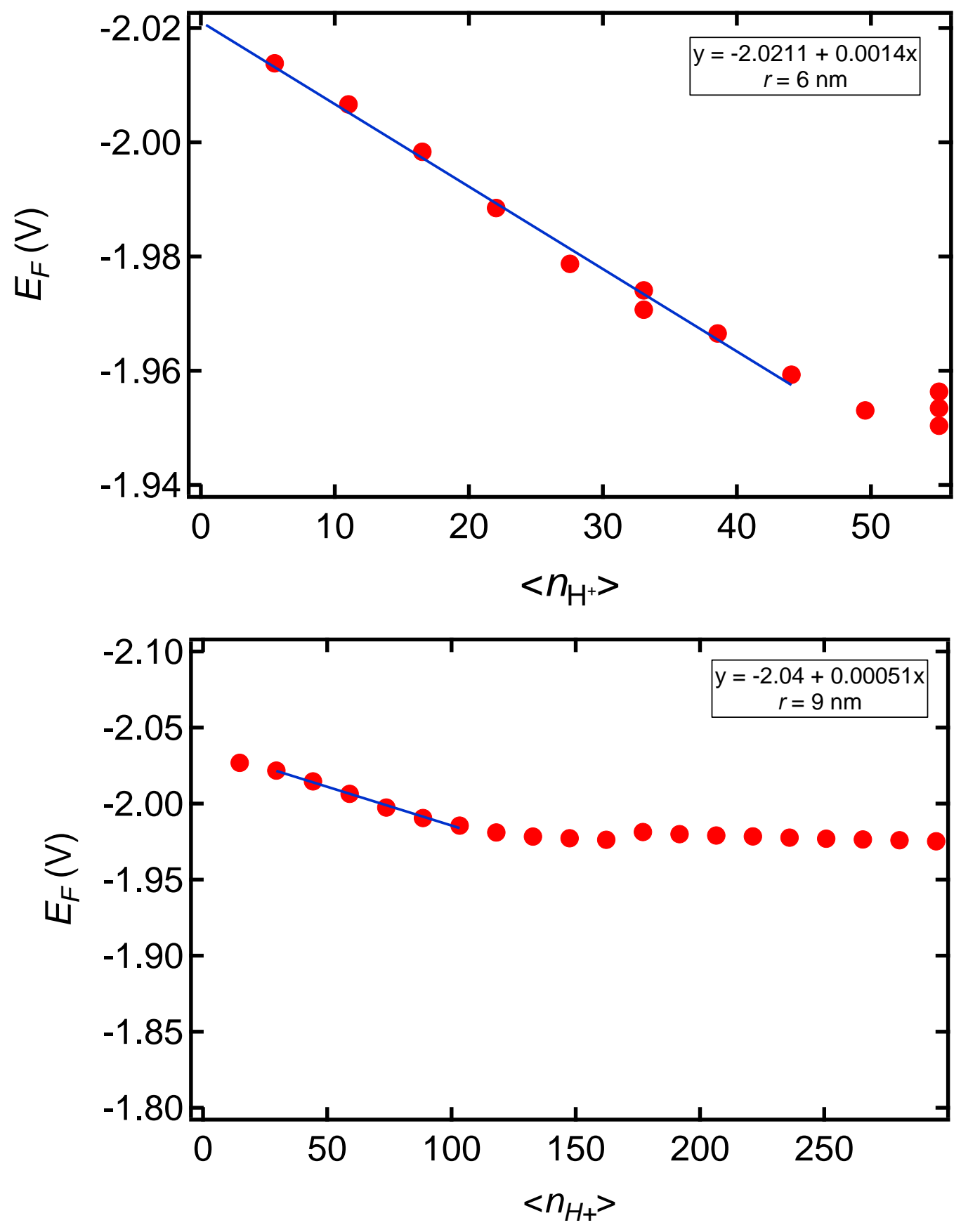

Constancy in $\boldsymbol{E}_{\boldsymbol{F}}$ with different amounts of $\boldsymbol{C o C p} *_{2}$. Equation 1 predicts that the value of $E_{F}$ changes with the ratio of $\mathrm{CoCp}^{*}{ }_{2} / \mathrm{CoCp}_{2}$. Varying the amount of $\mathrm{CoCp}^{*}{ }_{2}$ by two fold, but leaving $\left\langle n_{e_{-}}\right\rangle$unchanged gives a difference in $E_{F(\max )}$ of only $10 \mathrm{mV}$ (Figure S16). This analysis shows that although the concentration of CoCp* $*_{2}$ varies in the above experiments, the $E_{F(\max )}$ is relatively unaffected. 


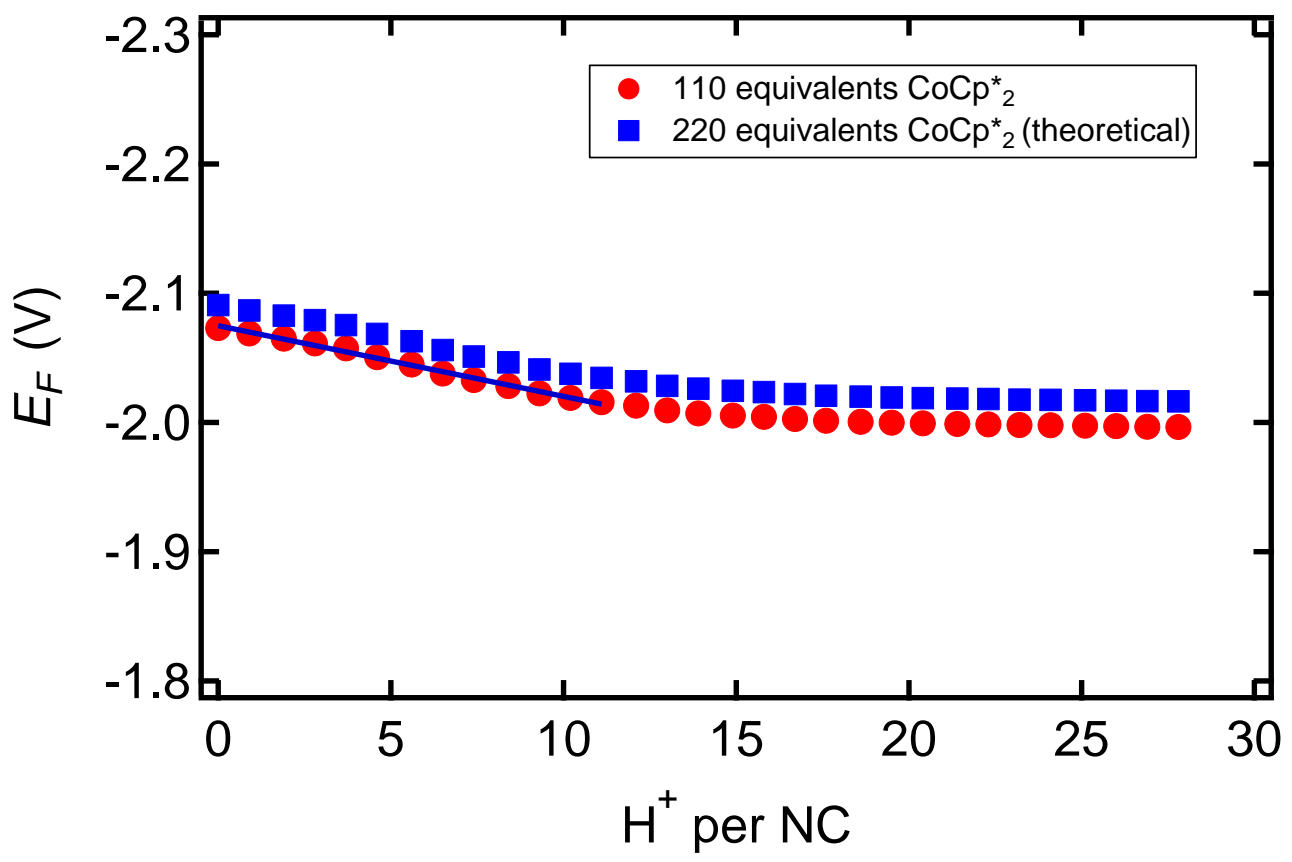

Figure S16. $\boldsymbol{E}_{\boldsymbol{F}}$ for $\mathrm{ZnO}$ NCs in Figure $5 \mathrm{~B}$, with double the amount of $\mathrm{CoCp}_{2}{ }_{2}$, with a fixed number of electrons transferred $\left(\mathrm{CoCp}^{*}{ }^{+}\right)$. The $E_{F(\max )}$ for 110 equivalents is -2.00 vs. $-2.01 \mathrm{~V}$ for 220 equivalents of CoCp*2.

Maximum carrier density on a linear scale.

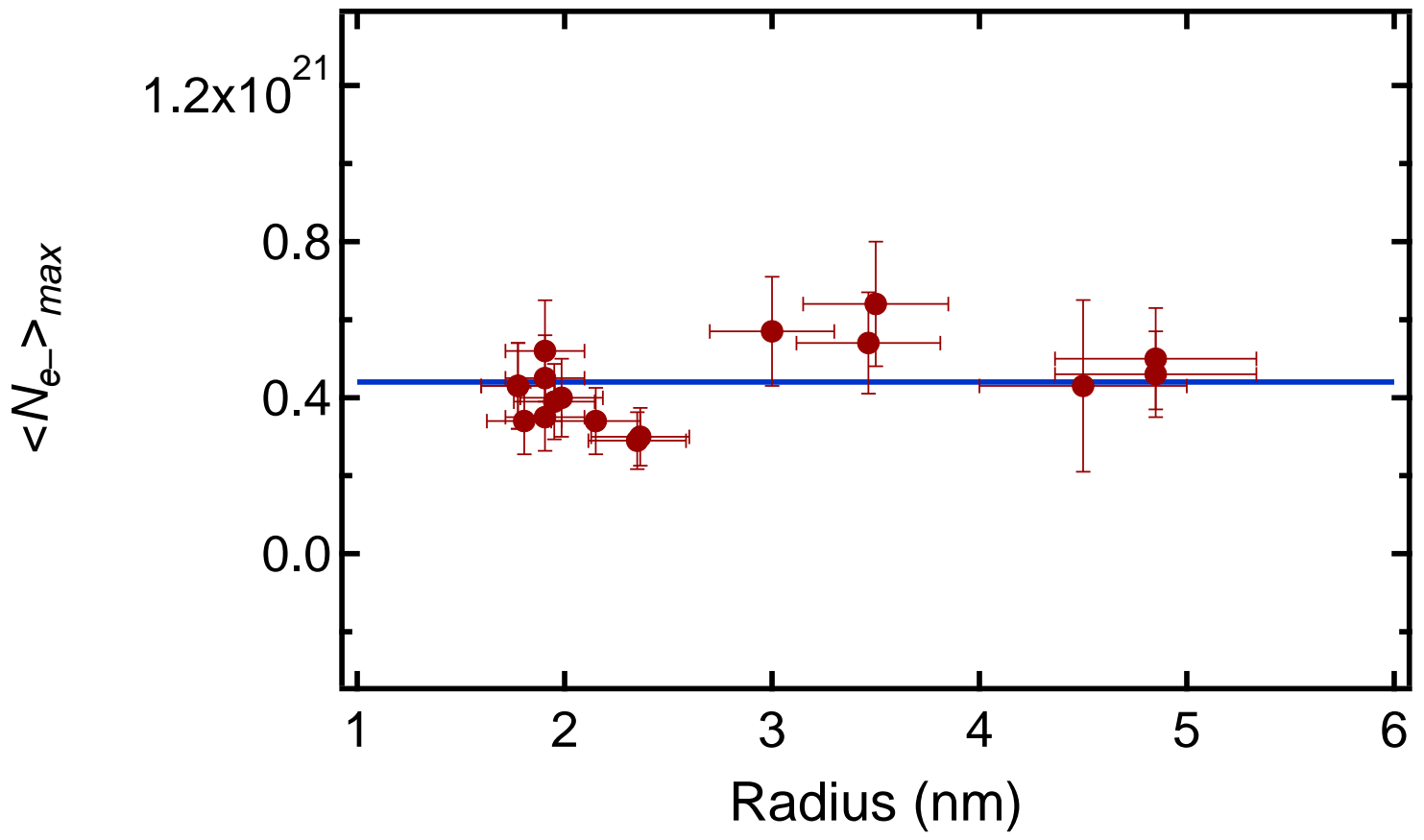

Figure S17. NC Size-Independent Carrier Density of ZnO NCs Reduced with CoCp*2 and Protons.

Analogous to Figure 3 in the main text, but plotted with linear axes. 


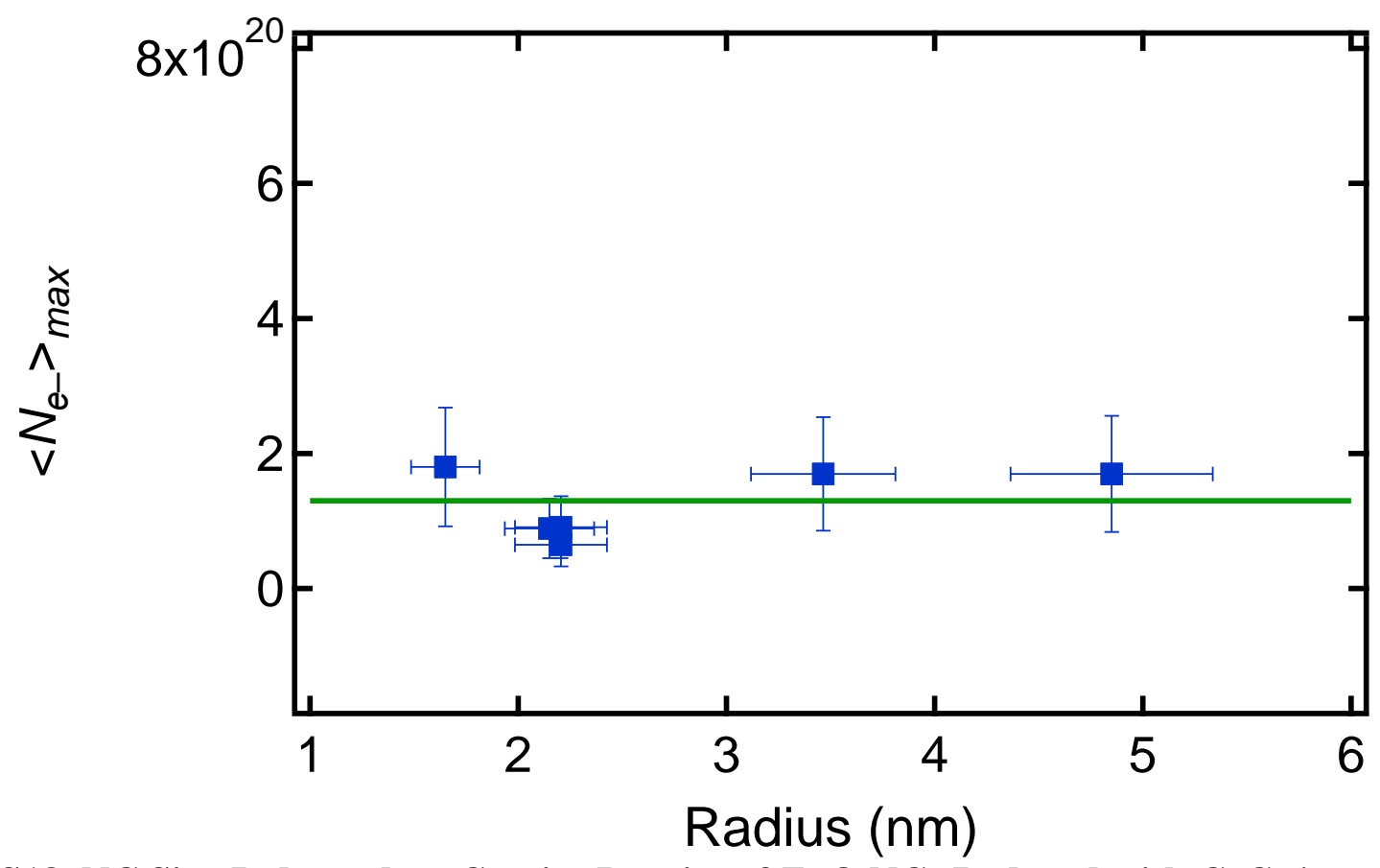

Figure S18. NC Size-Independent Carrier Density of ZnO NCs Reduced with CrCp*2 and Protons. Analogous to Figure 4 in the main text, but plotted with linear axes.

\section{References}

(1) Manner, V. W.; Markle, T. F.; Freudenthal, J. H.; Roth, J. P.; Mayer, J. M. Chem. Commun. $2008,256$.

(2) Brookhart, M.; Grant, B.; Volpe, A. F. Organometallics 1992, 11, 3920.

(3) Yakelis, N. A.; Bergman, R. G. Organometallics 2005, 24, 3579.

(4) Valdez, C. N.; Braten, M.; Soria, A.; Gamelin, D. R.; Mayer, J. M. J. Am. Chem. Soc. 2013, $135,8492$.

(5) Le Bras, J.; Jiao, H.; Meyer, W. E.; Hampel, F.; Gladysz, J. A. J. Organomet. Chem. 2000, 616, 54.

(6) Schwartz, D. A.; Norberg, N. S.; Nguyen, Q. P.; Parker, J. M.; Gamelin, D. R. J. Am. Chem. Soc. 2003, $125,13205$.

(7) Hayoun, R.; Whitaker, K. M.; Gamelin, D. R.; Mayer, J. M. J. Am. Chem. Soc. 2011, 133, 4228.

(8) Meulenkamp, E. A. J. Phys. Chem. B 1998, 102, 5566.

(9) Schrauben, J. N.; Hayoun, R.; Valdez, C. N.; Braten, M.; Fridley, L.; Mayer, J. M. Science 2012, 336, 1298.

(10) Germeau, A.; Roest, A.; Vanmaekelbergh, D.; Allan, G.; Delerue, C.; Meulenkamp, E. Phys. Rev. Lett. 2003, 90, 097401.

(11) Whitaker, K. M.; Ochsenbein, S. T.; Polinger, V. Z.; Gamelin, D. R. J. Phys. Chem. C 2008, $112,14331$.

(12) Goings, J. J.; Schimpf, A. M.; May, J. W.; Johns, R. W.; Gamelin, D. R.; Li, X. J. Phys. Chem. C 2014. 